\title{
Configurações
}

Revista de sociologia

$24 \mid 2019$

Imaginar "futuros" do trabalho, contextos e vivências subjetivas

\section{Representação da mobilidade e práticas de mobilização em empresas portuguesas: o caso de uma expatriação}

To choose or to be chosen? Exploring expatriate selection practices in Portuguese multinational companies

Choisir ou être choisi? Sélection d'expatriés au sein des entreprises multinationales portugaises

João Vasco Coelho

\section{OpenEdition}

\section{Journals}

\section{Edição electrónica}

URL: http://journals.openedition.org/configuracoes/7664

DOI: 10.4000/configuracoes.7664

ISSN: 2182-7419

\section{Editora}

Centro de Investigação em Ciências Sociais

\section{Edição impressa}

Paginação: 28-44

ISSN: 1646-5075

\section{Refêrencia eletrónica}

João Vasco Coelho, «Representação da mobilidade e práticas de mobilização em empresas portuguesas: o caso de uma expatriação », Configurações [Online], 24 | 2019, posto online no dia 18 dezembro 2019, consultado o 19 dezembro 2019. URL : http://journals.openedition.org/ configuracoes/7664; DOI : 10.4000/configuracoes.7664 
Coelho, João Vasco - Representação da mobilidade e práticas de mobilização em empresas portuguesas: o caso de uma expatriação. Configurações, vol. 24, 2019, pp. 28 -44.

\title{
Representação da mobilidade e práticas de mobilização em empresas portuguesas: 0 caso de uma expatriação
}

JOÃO VASCO COELHO*

CIES/ISCTE-IUL

\section{Resumo}

A mobilidade associada à prestação de trabalho tende a ser apresentada e representada com acento laudatório, no plano do discurso gestionário e organizacional: constitui uma oportunidade, um lugar de estímulo, de crescimento, de diferenciação. O presente artigo interroga os modos de representação contemporânea da mobilidade enquanto eixo de configuração da prestação de trabalho, explorando a forma como a mobilização para um regime de mobilidade concreto - uma expatriação - tem lugar no quotidiano gestionário das empresas portuguesas. Vinte e quatro casos individuais de mobilização constituem o corpus empírico da pesquisa, salientando a sua análise o incentivo diferencial da mobilidade, entendido enquanto espaço de oportunidade, que é colocado em prática pelas empresas.

Palavras-chave: mobilidade; mobilização; expatriação.

\begin{abstract}
To choose or to be chosen? Exploring expatriate selection practices in portuguese multinational companies

International mobility associated with provision of work in an expatriation context tends to be presented with a laudatory accent, in terms of managerial and organisational discourse: it is an opportunity, a place of stimulation, growth and personal differentiation. By exploring the way expatriate workers are identified and selected by a company, this article questions the developmental meaning commonly ascribed to an expatriation, as a context of univocal and universal access to career and personal development benefits. Twenty-four individual cases of expatriation observed in the context of the internationalisation processes of five companies, with Portuguese origin or national presence, constitute the empirical corpus of the research.
\end{abstract}

Keywords: mobility; mobilization; expatriation.

*E-mail: vasco.jcoelho@gmail.com 


\section{Résumé \\ Choisir ou être choisi ? Sélection d'expatriés au sein des entreprises multinationales portugaises}

La mobilité internationale associée au travail dans un contexte d'expatriation a tendance à être présentée avec un accent élogieux, en termes de discours managérial et organisationnel : c'est une opportunité, un lieu de stimulation, de croissance et de différenciation. En explorant la manière dont une entreprise identifie et sélectionne les travailleurs expatriés, cet article conteste le sens du développement généralement attribué à l'expatriation, en tant que contexte d'accès univoque et universel aux avantages de carrière et de développement personnel. Le corpus empirique de l'analyse est constitué de vingt-quatre cas individuels d'expatriation observés dans le cadre des processus d'internationalisation de cinq sociétés d'origine portugaise.

Mots-clés: mobilité; mobilisation; expatriation.

\section{Introdução}

A mobilidade associada à prestação de trabalho tende a ser hoje apresentada e representada com contornos benignos, laudatórios, no plano do discurso gestionário e organizacional (Costas, 2013): trata-se de uma oportunidade, de um lugar de estímulo, de diferenciação. Ir para fora é apresentado como condição de prosperidade, uma oportunidade, uma escolha desejável, tendente à otimização dos recursos detidos. É com intensidade que a apresentação da mobilidade como requisito ou como pressuposto normativo é vivida pelos indivíduos (Cresswell, 2006; Dorow, Roseman, \& Cresswell, 2017). A mobilidade delimita, neste sentido, um fenómeno social que não é apenas redutível a uma deslocação espacial, corpórea, representando um conjunto amplo de materialidades móveis inerentes à relação social e à ação individual e organizacional contemporânea, que resultam da dissolução, da desaparição ou da hibridação de isolats sociais e sociodemográficos obedientes a arquétipos comunitários, outrora notadamente persistentes no tempo.

A noção, assim difundida, em termos universais e inequívocos, de mobilidade como oportunidade, contrasta com a existência de evidências empíricas que ilustram o modo como o acesso à mobilidade (à oportunidade) é constrangido por estratégias organizacionais de gestão de recursos humanos e de incentivo diferencial da mobilidade (Doherty \& Dickmann, 2009). É possível identificar, com efeito, a existência de práticas seletivas que se traduzem na possibilidade das características dos indivíduos recrutados e mobilizados pelas empresas diferirem, por via de regra, das dos não-mobilizados, e na existência de atributos (e.g., a idade dos indivíduos, a condição familiar) que tornam mais provável o desencadear da mobilidade (Peixoto, 1998; Elliot \& Urry, 2010). 
$\mathrm{Na}$ pesquisa reportada pelo presente artigo, a representação, expressa e difundida de modo dominante, de mobilidade como oportunidade (de ganhar mundo, de sair da zona de conforto) constitui o eixo de problematização base. As práticas de mobilização associadas à prestação de trabalho num regime de mobilidade particular - uma expatriação -, especialmente relevante na concretização de processos de internacionalização de empresa (Caligiuri e Bonache, 2016), delimitaram o referente empírico da pesquisa que foi concretizada: O acesso a uma condição de mobilidade, numa empresa, define um quadro que se escolhe, ou trata-se, ao invés, de uma experiência de/para escolbidos?

Em termos analíticos, procurou articular-se, em termos duais (Mouzelis, 2008), a perspetiva das empresas, responsáveis primeiros pela organização da prestação de trabalho num contexto de expatriação, com a perspetiva dos indivíduos expatriados, coprotagonistas, em termos vividos, das mesmas. Com esta opção, visou-se reconhecer a importância e os efeitos da experiência de subjetivação individual de uma condição material de prestação de trabalho de existência (Bourdieu, 1989 [1977]). À luz desta perspetiva dual, a motivação individual apensa à aceitação de uma condição de mobilidade e os processos organizacionais contribuintes para a sua valorização enquanto contexto de oportunidade(s), assumem uma geometria variável. Para uns, a subscrição da ida pode ser identificada como um prémio (de carreira), um símbolo de distinção; para outros, poderá representar uma necessidade, uma fuga (ao desemprego, a uma rotina sem estímulo, a uma circunstância familiar desestruturada); para outros poderá figurar, de facto, como uma oportunidade - de ganhos materiais significativos, de viagens para os filhos, de promoção e ganhos de visibilidade no mercado interno de trabalho da empresa, de aprendizagem, um modo de aquisição de uma identidade cosmopolita, de uma cultura internacional, de uma carreira global, condição e símbolo de pertença às elites cinéticas (Costas, 2013) constituídas pelos movimentos de globalização económica, e nestes, por processos de internacionalização de organizações e de empresas.

\section{Enquadramento teórico}

As mobilidades contemporâneas, expressas num plural em si mesmo paradigmático, significativo (Cresswell, 2006; Urry, 2007), são hoje reificadas como bem de consumo, uma fonte de poder e de estatuto social, constituindo um fator de segmentação social que reflete, recompõe ou reforça, no quotidiano, hierarquias e desigualdades, implicando novas combinações de presença e de ausência, de proximidade e de distância, de diasporização das relações sociais. A mobilidade é perspectivada, deste modo, como pressuposto cardinal das e nas vidas sociais (e organizacionais) contemporâneas (Urry, 2007). 
A produção em massa materializada pela fabricação de bens estandardizados suscitou o estabelecimento de práticas de gestão que possibilitassem a regulação do tempo e dos movimentos, cujo êxito dependia da sedentarização dos trabalhadores num local fixo. Nos termos de diferentes autores (Gherardi, 2009; Costas, 2013), observa-se que a mobilidade física, doméstica ou internacional, acompanha, de modo especialmente consistente, a configuração ideológica subjacente aos processos de globalização económica, e é congruente, em termos normativos, com noções de trabalho e de empresa que são perspetivadas como objeto de dispersão e de fragmentação espacial, através de diferentes fronteiras - geográficas, sociais e culturais. Nesta perspetiva, estar em movimento não é mais uma questão de escolha, é um requisito que se associa a cenários de inclusão e de exclusão social (Cresswell, 2006), produto e produtor de relações de poder, ao representar uma possibilidade de fuga à normalização proposta pelo ideário socioeconómico de mercado. Trata-se de uma fuga que se encontra disponível apenas para alguns (Elliott \& Urry, 2010), dotando a mobilidade dos atributos concedidos às categorias cuja apropriação desigual reforça e espelha uma hierarquia de posições sociais, um estilo de vida que simboliza o acesso a um privilégio, a uma condição de diferenciação de um estatuto social, a excepcionalidade de uma experiência particular.

A prestação de trabalho delimita, deste modo, um fenómeno propício à exploração das implicações sociais e organizacionais da mobilidade (Gherardi, 2009) e, em particular, ao questionar da visão que a tende a reificar enquanto experiência impoluta de libertação, de escapismo, uma condição de habilitação e de manutenção de competitividade de empresas, das famílias, dos indivíduos (Elliott \& Urry, 2010). Importa considerar, a este respeito, que a apologia do potencial libertador da mobilidade pode contemplar distorções e generalização, já que, neste domínio como noutros da vida social e organizacional, o acesso à mobilidade comporta segmentação, delimitando uma realidade que é em si mesmo heterogénea, proporcionando um elemento diferencial, desejado ou não, nas trajetórias socioprofissionais dos indivíduos. Com efeito, é possível distinguir aqueles que acedem à mobilidade de forma involuntária, como um imperativo indutor de insegurança e de um sentido de desfiliação, e aqueles que acedem ao movimento como fruto de uma escolha pessoal, uma elite cinética (Costas, 2013) para quem a mobilidade representa um putativo marcador de distinção social, um veículo de acumulação de prestígio e de recursos pessoais, disponíveis no estabelecimento de novas relações sociais e de identidades pessoais que se afirmam como exclusivas, superiores, livres de constrangimento (McKenna et al., 2015). Regista-se, deste modo, que os indivíduos podem experimentar a mobilidade de modo diferencial, ora como um recurso crítico (escolhido), ora como um imperativo (exterior, forçado).

Devido à especificidade da sua génese (organizacional), e à subsistência de um enquadramento organizacional formal dos indivíduos no decurso do 
período de mobilidade (Caligiuri \& Bonache, 2016), uma expatriação constitui hoje, em termos empíricos, um locus de observação privilegiado das representações e das práticas existentes no domínio empresarial sobre a mobilidade, em sentido lato, e sobre a mobilidade associada à prestação de trabalho, em particular. Uma expatriação tende a ter lugar no quadro de programas estruturados, formais, de mobilidade geográfica associada à prestação de trabalho. A mobilização tende a implicar a intersecção e a consideração de domínios de necessidade organizacional, e de motivação e interesse individual. A este nível, importa referir que as estratégias e práticas organizacionais de mobilização e incentivo da mobilidade tendem a não ser informadas pela aleatoriedade. Para a prestação de trabalho num quadro de expatriação, a mobilização pode decorrer de dispositivos informais de gestão (Harris \& Brewster, 1999; Anderson, 2005), uma orientação inspirada em representações segmentárias da mobilidade e dos mercados de trabalho internos das empresas, que tende a conceder uma atenção (e investimento) particular a segmentos específicos de trabalhadores, identificados como detendo elevada capacidade ou potencial (Makela et al., 2010), produzindo-se, deste modo, restrições à possibilidade de acesso generalizado à detenção de experiência de mobilidade e de prestação de trabalho em contexto internacional, por parte dos indivíduos.

\section{Materiais e métodos}

A pesquisa reportada pelo presente artigo teve lugar entre os meses de Janeiro de 2016 e Junho de 2017. Com a pesquisa realizada, visou-se aprofundar o conhecimento relativo às condições de acesso e controlo de acesso a um quadro de mobilidade específico (uma expatriação), um empreendimento cuja relevância decorre do impacto que lhe é atribuído, em termos socioeconómicos e organizacionais. A estratégia de pesquisa assumiu, em função da modelação deste desiderato, uma feição qualitativa, centrando-se na análise intensiva de uma seleção de campos de observação empírica. Com o uso de múltiplos contextos de análise, procurou-se ir ao encontro da profundidade de interpretação, do sentido de parcimónia e equilíbrio que tende a enformar uma análise e problematização de estudos de caso suportada em evidências recolhidas em múltiplos contextos empíricos (Eisenhardt \& Graebner, 2007).

Atendendo ao horizonte de problematização teórica estabelecido para a pesquisa, a seleção de contextos de observação correspondeu à identificação de um conjunto de universos empresariais para a concretização da vertente empírica da pesquisa. $\mathrm{Na}$ identificação destes contextos, procurou atender-se à possibilidade de cada universo empresarial poder representar uma situação total, em relação à problemática em estudo (Ragin \& Amoroso, 2011). A procura de diversidade, por um lado, e de tipicidade (de setores de atividade, de 
dimensão e volume de negócio, de trajetórias de internacionalização empresarial e de práticas de expatriação e mobilidade internacional de trabalhadores), por outro, enformou a necessidade de considerar múltiplos contextos empresariais, supondo a existência de heterogeneidade nos domínios perfilhados em termos analíticos. Os cinco contextos empresariais considerados como espaço de observação empírica são apresentados de modo sintético na Tabela 1.

Ao nível da recolha de informação empírica, foram empregues dois tipos de técnicas: a recolha e a análise de fontes estatísticas e documentais secundárias, públicas ou facultadas pelas empresas consideradas pelo estudo, um procedimento transversal à pesquisa, e a entrevista. No que concerne às fontes estatísticas e documentais utilizadas, o seu emprego visou localizar a realidade em estudo em termos macro. O foco das entrevistas foi duplo, em função do interlocutor considerado: a procura de caracterização e reconstituição das linhas de atuação empresarial, das representações da mobilidade e das práticas de mobilização de trabalhadores (a expatriar), no caso de responsáveis de gestão de empresa; a exploração dos atributos caracterizadores do acesso a uma expatriação enquanto experiência vivida, identificando tensões eventualmente existentes entre condicionantes estruturais e orientações da ação individual, no caso de trabalhadores expatriados. Foram realizadas 37 entrevistas individuais, em regime presencial ou remoto, 13 a responsáveis de gestão de empresa, 24 a trabalhadores cuja trajetória pessoal, profissional e familiar estava a ser ou tinha sido pontuada, com maior ou menor intensidade, pela prestação de trabalho num quadro de expatriação (assim definido e referido pelas empresas). Uma caracterização geral dos 24 trabalhadores que foram entrevistados é apresentada na Tabela 2 .

As entrevistas a responsáveis de gestão de empresa foram presenciais e tiveram uma duração média de 80 minutos. Das 24 entrevistas a trabalhadores expatriados, 13 tiveram lugar em regime remoto, via Skype ou interface análogo, sendo que em 4 destes casos o registo assegurado foi apenas áudio, por debilidades de infraestrutura de comunicação. As entrevistas a trabalhadores expatriados tiveram uma duração média de 120 minutos. A título sensibilizador, fez-se uso de um critério de saturação de informação (Strauss \& Corbin, 1998) na limitação do número de casos individuais considerado em/para cada empresa.

Dada a orientação estratégica da pesquisa e o horizonte de problematização perfilhado, procurou-se constranger, de modo deliberado, o perfil dos indivíduos a entrevistar, à imagem do observado na identificação dos contextos empresariais adotados como instância de análise empírica. Cinco critérios de seleção foram partilhados com o ponto de contacto existente em cada contexto empresarial, tipicamente um gestor de recursos humanos indigitado para o cumprimento da função de regulação do acesso ao campo empírico (gatekeeping) (Shenton \& Hayter, 2004). O primeiro destes critérios diz respeito à 
trajetória pessoal e profissional dos indivíduos e à intensidade, em termos relativos, de internacionalização desta trajetória. A condição presente em relação à mobilidade (expatriado vs. repatriado) definiu um segundo critério de seleção. A duração da mobilidade atual ou mais recente (em caso de regresso, de repatriação) constitui um terceiro critério. O ponto de articulação biográfica (início, expansão, estagnação, desfecho de trajetória) definiu um quarto critério, e, por fim, a condição familiar (existência de filhos, de ascendentes dependentes, de família acompanhante) delimitou um último fator a considerar.

Os materiais empíricos reunidos foram objeto de análise e categorização temática com o apoio de software específico (MaxQDA v.12). O trabalho analítico procurou articular a perspetiva gestionária e organizacional, com as perspetivas individuais relativas a experiências concretas, vividas, de mobilidade associadas à prestação de trabalho referida como constituindo uma expatriação. Uma perspetiva dupla foi adotada na explanação dos resultados da análise dos materiais empíricos: a) a exploração de regularidades observáveis entre os diferentes contextos e casos considerados (cf. secção Resultados); e b) a discussão de aspetos particulares, salientes além das regularidades observadas (cf. secção Discussão). Atendendo ao dever e ao compromisso de confidencialidade e de manutenção do anonimato inerente às tarefas de recolha e tratamento de informação empírica, a identidade dos contextos empresariais e dos indivíduos entrevistados em cada contexto foi omitida, na apresentação e na discussão dos resultados da pesquisa.

Tabela 1. Caracterização geral dos contextos empresariais analisados

\begin{tabular}{|c|c|c|c|c|c|c|c|c|c|c|}
\hline $\begin{array}{l}\text { Contexto } \\
\text { empresarial }\end{array}$ & Setor de actividade & Governance & $\begin{array}{c}\text { Volume de } \\
\text { negócios (2016) }\end{array}$ & $\begin{array}{l}\text { Dimensāo(RH) } \\
\text { (2016) }\end{array}$ & $\begin{array}{l}\text { Inicio de } \\
\text { atividade }\end{array}$ & $\begin{array}{c}\text { Afirmação de } \\
\text { inter nacionalização } \\
\text { (ano de inicio) }\end{array}$ & $\begin{array}{c}\text { Afir mação de } \\
\text { internacionaliz ação } \\
\text { (\# paises/merc ados) }\end{array}$ & $\begin{array}{l}\text { Definição de politica } \\
\text { de expatriação (ano } \\
\text { de inicio) }\end{array}$ & $\begin{array}{c}\text { \# Individuos } \\
\text { expatriados } \\
\text { (2017) }\end{array}$ & $\begin{array}{c}\% \text { Individuos } \\
\text { expatriados (rel } \\
\text { total) (2017) }\end{array}$ \\
\hline "Luz de Sempre" & Utilities -Energia & $\begin{array}{l}\text { Privada (com } \\
\text { participaçăo } \\
\text { pública) }\end{array}$ & $3.759 \mathrm{M}$ euros & 12000 & 1976 & 1996 & 14 paises & 2014 & 25 & $(<1 \%)$ \\
\hline "Grossista" & Retalho e Distribuiçăo & Privada & $5.376 \mathrm{M}$ curos & 44400 & 1959 & 1990 & 89 paiscs & 2012 & 30 & $(<1 \%)$ \\
\hline "Excel" & Consultoria de Gestāo & Privada & $80.2 \mathrm{M}$ euros & $\begin{array}{l}244400 \\
(2300 \mathrm{em} \\
\text { Portug al) }\end{array}$ & 2002 & 1993 & $\begin{array}{l}150 \text { paises. } \\
\text { presença local em Portug al. }\end{array}$ & 2013 & 100 & $4.35 \%$ \\
\hline "Tabique" & Construção & Privada & $2210 \mathrm{M}$ euros & 25.383 & 1946 & 1946 & 25 paises & 2010 & 1264 & $498 \%$ \\
\hline "V\&V" & $\begin{array}{l}\text { IT - Desenvolvimento } \\
\text { de Software }\end{array}$ & Privada & $30 \mathrm{M}$ euros & 400 & 1998 & 1999 & 5 paises & 2009 & 41 & $10.25 \%$ \\
\hline
\end{tabular}

Fonte: Relatórios anuais de atividade de empresa; Elaboração própria. 
Tabela 2. Elementos de caracterização geral dos indivíduos entrevistados

\begin{tabular}{|c|c|c|c|c|c|c|c|c|c|c|}
\hline Entreristado & $\begin{array}{l}\text { Contexto } \\
\text { empresarial }\end{array}$ & $\begin{array}{l}\text { Posição na estrutura de } \\
\text { emprego }\end{array}$ & Idade & Sexo & Habilitação Académica & $\begin{array}{c}\text { Trajetória } \\
\text { Profissional Externa } \\
\text { (\# empregadores) }\end{array}$ & $\begin{array}{l}\text { Experiência } \\
\text { Profissional (\# } \\
\text { anos, total) }\end{array}$ & $\begin{array}{c}\text { Experiência } \\
\text { Profissional (\# anos, } \\
\text { no actual ou último } \\
\text { empregador) }\end{array}$ & $\begin{array}{c}\text { Duração de } \\
\text { Expatriação } \\
\text { (\# anos) }\end{array}$ & Ponto de articulação biográfica \\
\hline "Isaac" & "Luz de Sempre" & Gestão de topo & 65 & $\mathrm{M}$ & $\begin{array}{c}\text { Licenciatura (pré-Bolonha), Engenharia } \\
\text { Electrotécnica }\end{array}$ & 2 & 44 & 37 & 17 & 3. Planalto-Estagnação \\
\hline "Joana" & "Luz de Sempre" & Quadro & 39 & $\mathrm{~F}$ & Licenciatura em Contabilidade & 7 & 20 & 12 & 1 & 3. Planalto-Estagnação \\
\hline "Heitor" & "Excel" & Quadro & 34 & M & $\begin{array}{l}\text { Mestrado (Bolonha), Engenharia } \\
\text { Informática }\end{array}$ & 3 & 10 & 3 & 4.5 & 2. Expansão \\
\hline "Gaspar" & "Luz de Sempre" & Quadro & 28 & M & MBA, Gestão & 2 & 4 & 3 & 1.5 & 1. Inicio \\
\hline "Antónia" & "Luz de Sempre" & Quadro & 33 & $\mathrm{~F}$ & Licenciatura (pré-Bolonha), Gestão & 2 & 11 & 9 & 2 & 3. Planalto-Estagnação \\
\hline "Gil" & "Luz de Sempre" & Gestão intermédia & 67 & $\mathrm{M}$ & $\begin{array}{l}\text { Licenciatura (pré-Bolonha), Engenharia } \\
\text { Electrotécnica }\end{array}$ & 1 & 38 & 38 & 5 & 4. Desfecho \\
\hline "Silvestre" & "Luz de Sempre" & Quadro & 29 & $\mathrm{M}$ & Mestrado (pós-Bolonha) Gestão & 1 & 7 & 7 & 0.4 & 1. Inicio \\
\hline "Dinis" & "Excel" & Quadro & 33 & M & $\begin{array}{l}\text { Mestrado (Bolonha), Engenharia } \\
\text { Informática }\end{array}$ & 5 & 10 & 2.5 & 4 & 2. Expansão \\
\hline "Enzo" & "Luz de Sempre" & Gestão de topo & 71 & M & $\begin{array}{l}\text { Licenciatura (pré-Bolonha), Engenharia } \\
\text { Electrotécnica }\end{array}$ & 2 & 36 & 30 & 13 & 2. Expansão \\
\hline "Francisco" & "Luz de Sempre" & Gestão intermédia & 67 & $\mathrm{M}$ & $\begin{array}{l}\text { Licenciatura (pré-Bolonha), Engenharia } \\
\text { Electrotécnica }\end{array}$ & 4 & 31 & 25 & 5 & 3. Planalto-Estagnação \\
\hline "Carlos" & "V\&V" & Gestão intermédia & 38 & M & $\begin{array}{l}\text { Licenciatura (pré-Bolonha), Engenharia } \\
\text { Informática }\end{array}$ & 1 & 17 & 17 & 3 & 3. Planalto-Estagnação \\
\hline "José" & "Luz de Sempre" & Gestão intermédia & 60 & $\mathrm{M}$ & $\begin{array}{l}\text { Licenciatura (pré-Bolonha), Engenharia } \\
\text { Informática }\end{array}$ & 1 & 33 & 33 & 4 & 3. Planalto-Estagnação \\
\hline "Xavier" & "V\&V" & Gestão intermédia & 38 & M & $\begin{array}{l}\text { Licenciatura (pré-Bolonha), Engenharia } \\
\text { Informática }\end{array}$ & 1 & 15 & 15 & 2 & 3. Planalto-Estagnação \\
\hline "Rui" & "V\&V" & Quadro & 30 & $\mathrm{M}$ & $\begin{array}{l}\text { Licenciatura (Bolonha), Engenharia } \\
\text { Informática }\end{array}$ & 2 & 7 & 5 & 2 & 2. Expansão \\
\hline "Violeta" & "Tabique" & Quadro & 34 & $\mathrm{~F}$ & $\begin{array}{c}\text { Licenciatura (Pré-Bolonha), Psicologia } \\
\text { Clinica }\end{array}$ & 2 & 10 & 9 & 1.5 & 3. Planalto-Estagnação \\
\hline "Nuno" & "V\&V" & Gestão intermé dia & 46 & M & Licenciatura (pré-Bolonha), Gestão & 3 & 24 & 10 & 2 & 3. Planalto-Estagnação \\
\hline "Filipa" & "V\&V" & Quadro & 28 & $\mathrm{~F}$ & Mestrado (Bolonha), Matemática & 1 & 3 & 3 & 0.5 & 1. Inicio \\
\hline "Augusto" & "V\&V" & Quadro & 33 & M & $\begin{array}{l}\text { Licenciatura (Bolonha), Engenharia } \\
\text { Informática e de Sistemas }\end{array}$ & 1 & 9 & 9 & 6 & 2. Expansão \\
\hline "Filipe" & "V\&V" & Quadro & 37 & M & $\begin{array}{l}\text { Licenciatura (pré-Bolonha), Engenharia } \\
\text { Informática }\end{array}$ & 1 & 13 & 13 & 7 & 2. Expansão \\
\hline "Aurélio" & "Tabique" & Gestão intermédia & 67 & $\mathrm{M}$ & Licenciatura (pré-Bolonha), Economia & 3 & 38 & 36 & 18 & 2. Expansão \\
\hline "Mário" & "Tabique" & Quadro & 38 & M & $\begin{array}{c}\text { Licenciatura (pré-Bolonha), Engenharia } \\
\text { Civil }\end{array}$ & 1 & 15 & 15 & 2.5 & 2. Expansão \\
\hline "Miguel" & "Tabique" & Quadro & 40 & $\mathrm{M}$ & MBA, Finanças & 2 & 21 & 17 & 5 & 2. Expansão \\
\hline "Tiago" & "Tabique" & Quadro & 30 & M & Mestrado (Bolonha), Engenharia Civil & 2 & 7 & 5 & 6 & 1. Inicio \\
\hline "Duarte" & "Tabique" & Quadro & 38 & M & $\begin{array}{c}\text { Licenciatura (pré-Bolonha), Engenharia } \\
\text { Civil }\end{array}$ & 1 & 15 & 15 & 7 & 2. Expansão \\
\hline
\end{tabular}

Fonte: Elaboração própria. 


\section{Resultados}

$\mathrm{Na}$ análise que se apresenta, a caracterização das representações da mobilidade e das práticas de mobilização em uso (para uma expatriação, entendido enquanto quadro ou regime de mobilidade dotado de enquadramento organizacional), é concretizada com o apoio de ilustrações empíricas procedentes do material que foi recolhido, enunciados cuja função primordial é a elucidação do argumento apresentado a cada momento. Em relação ao modo como o acesso e o controlo do acesso a uma expatriação é perspetivado pelos responsáveis de empresa e pelos indivíduos expatriados que foram entrevistados, importa atender, a título de regularidade, a três observações empíricas, que se explanam de seguida.

\subsection{0 acesso a uma condição de mobilidade é objeto de regulação organizacional deliberada}

À diferenciação de motivos e de objetivos estratégicos de internacionalização que foi observada, em termos analíticos, associa-se uma diferenciação de veículos de internacionalização, e um uso diferencial da mobilidade internacional de trabalhadores que é colocada em prática neste contexto. Diferentes objetos (e.g., um produto, uma marca, capital, conhecimento), diferentes veículos organizacionais (e.g., um projeto internacional, um consórcio, uma filial) suscitam diferentes condições de constrangimento de recursos, em particular no referente ao espaço e à valorização (central ou subsidiária) reservada à mobilidade e à mobilização internacional de trabalhadores. A par de uma expatriação, tendem a coexistir, em termos formais, outras modalidades de mobilidade internacional de trabalhadores, com diferentes periodizações e enquadramentos organizacionais (e.g., projeto, joint-venture, consórcio, função intra-organizacional), que se destinam, à partida, a diferentes segmentos funcionais de trabalhadores.

Decorrendo das práticas de mobilização existentes, as escolhas realizadas não são aleatórias. O recrutamento e a mobilização interna, e, em particular, os convites e as práticas de identificação direta constituem uma prática prevalecente, por oposição ao recrutamento externo ou autoproposto. $\mathrm{O}$ acesso a um quadro de expatriação decorreu, na totalidade dos 24 casos individuais considerados, de um recrutamento interno, um dado que contrasta com o benchmark de referência neste domínio: 15 a 20\% de taxa de uso de recrutamento externo (Brookfield GRS, 2016). Em 63\% dos casos considerados (15 dos 24 trabalhadores entrevistados), o recrutamento interno teve lugar na sequência de um convite, de uma iniciativa deliberada, dirigida, da empresa. Com efeito, nos casos considerados, no acesso a uma expatriação, o convite direto predomina (e.g., "Luz de Sempre”, “Tabique”, "V\&V”), assim como os "pacotes retributivos diferenciados em função de grupos funcionais de referência” (Gestor de RH, grupo “Tabique”), que sinalizam condições particulares de subsidiação do desempenho individual, e a valoração específica, diferencial, da natureza da função desempenhada (a desempenhar) pelo trabalhador mobilizado. 
Há convites, em contextos específicos, porque é necessário constituir ou preservar, em termos relacionais, um sentido de confiança. A segmentação de diferentes modalidades de prestação de trabalho em contexto internacional, a definição diferencial, utilitarista, das “regalias” (Francisco) associadas à prestação de trabalho num contexto de expatriação, aparenta relacionar-se com a necessidade de controlo organizacional da mobilização de trabalhadores a um contexto de exposição (abertura) inter ou transorganizacional, a uma oportunidade conducente à aquisição de uma vantagem, de um valor diferenciador (ter ou não uma trajetória pessoal marcada pela experiência internacional) que deve ser objeto de ponderação específica (pela organização).

\subsection{As práticas de mobilização espelham relações e eixos de seg- mentação existentes ao nível dos mercados internos de trabalho}

No concernente às práticas de mobilização que foram observadas em termos empíricos, importa referir que o cliente e o projeto (realizado para um cliente) operam, em contextos organizacionais densamente projetificados (e.g., grupo "Excel”, empresa "V\&V"), como agentes de estruturação do espaço de mobilidade existente, de configuração de oportunidades de trabalho objetivas, de segmentação de requisitos e de valorização diferencial da mobilidade enquanto condição material descritora da especificidade de um regime particular de prestação de trabalho. Observa-se, nos contextos empresariais analisados, que o investimento de um cliente (estrangeiro) surge e opera como força centrífuga: primeiro, de empresas, depois, de trabalhadores.

O projeto e o cliente constituem duas figuras centrais na configuração material (e expressiva) da situação de trabalho (internacional) daquele que é mobilizado, no contexto do grupo "Excel". Neste contexto empresarial, a mobilização de trabalhadores tem lugar em função da existência de projetos internacionais, da continuidade de existência de projetos com um dado cliente, uma circunstância que apresenta o projeto internacional, como locus situado de práticas de gestão de recursos, de exercício localizado de influência, de produção bottom-up de situações de trabalho particulares, que comportam implicações na gestão dos mercados internos de trabalho (co)existentes nas empresas.

A empresa "V\&V" procura estar onde os seus clientes estão. No contexto desta empresa, nos processos de recrutamento e mobilização de um trabalhador para um quadro de expatriação, uma decisão de seleção, um convite, pode ser influenciado por diferentes atores, entre os quais importa destacar o poder de regulação do cliente. Neste quadro, reflexo do acento segmentário das políticas existentes, a mobilidade despoletada por iniciativa do próprio indivíduo tende a ser considerada, em termos gestionários, como um subproduto, ao qual se destinam condições diferenciadas, um acesso constrangido à mobilidade (como oportunidade). 
Nos casos e nos contextos analisados, a seletividade apensa ao controlo do acesso a uma situação de expatriação não gera, em si mesmo, segmentação dos mercados internos e externos de trabalho. Os processos de escolha decorrem desta, e da influência de interações situadas com agentes internos ou externos, em particular no caso de funções diferenciadas (de representação institucional) ou particularmente especializadas (para desempenhos em contexto de projeto), e do acento segmentário das políticas e das práticas de mobilização existentes, espelhando-o, reforçando-o nos seus processos constitutivos. Constitui um exemplo do referido, as múltiplas referências registadas ao acesso que decorre de um convite direto, baseado na proximidade, na confiança pessoal, e a existência de escolhas que decorrem da valorização de um currículo de um trabalhador efetuada pelo cliente de um projeto:

"Existem sempre convites e existem sempre candidaturas. Não conheço as percentagens, mas existem sempre estas duas tipologias de acesso". (Silvestre; Grupo "Luz de Sempre")

"Estes lugares, julgo que sabe, são de nomeação, dependem um pouco da administração". (Francisco; Grupo "Luz de Sempre”)

"Fez agora em Dezembro (de 2016) um ano, que o CEO da empresa me chamou e me disse que precisava da minha ajuda. Eu já tinha recusado duas vezes este projeto em Angola por razões pessoais e familiares". (Nuno; Empresa "V\&V")

"Este foi o primeiro desafio que aceitei: ir um mês e voltar, ir um mês e voltar, ir um mês e voltar. Depois disto, comprou-se uma das quatro empresas que o meu grupo avaliou, e eu fui convidado a ficar no Brasil, nessa empresa, pela experiência que já tinha das avaliações”. (Isaac; Grupo "Luz de Sempre")

"Um dia recebo uma chamada, em que me pediram para ir a Coimbra, onde me perguntaram se queria ir para o Brasil. [Um convite?] Sim, um convite feito formalmente por um dos anteriores administradores da empresa, que me conhecia". (Francisco; Grupo "Luz de Sempre")

\subsection{0 interlocutor e o discurso organizacional constituem operadores de mobilização relevante}

A mobilidade e a prestação de trabalho em contexto internacional é objeto de representações e de uma valoração diferencial, em termos institucionais, uma circunstância que se observa ao nível do discurso que é produzido, e que é, 
em alguns contextos, cristalizado em documentos e em nomenclatura formal de gestão. A situação em apreço (a mobilidade; uma expatriação) é tida como uma "oportunidade" (grupo "Luz de Sempre”), constitui um "desafio" (grupo "Grossista"). Há um conjunto de vantagens objetivas que surgem associadas ao desempenho de trabalho no quadro de uma expatriação. As vantagens podem ser mais ou menos objetivas, podem ser declaradas de modo mais ou menos ostensivo. Podendo não constituir, em si mesmo, um elemento de motivação, a existência ou a afirmação da existência de "vantagens" (Rui; Miguel), de "regalias" (Francisco), pode contribuir para forjar um enquadramento situacional que favorece o constrangimento da escolha individual, em função do fomento da perceção de existência de (maior) homologia entre interesses organizacionais e interesses individuais.

Enquadrar, em termos gestionários e organizacionais, o sentido de distância e multilocalização que se associa a uma expatriação (Caligiuri e Bonache, 2016), fazendo subsistir bases de agregação coletiva, define um desafio particular para empresas, para os gestores nas empresas. Neste contexto, a mobilização para a participação numa expatriação pode implicar acionar táticas particulares, um exercício situado de influência, de persuasão direta, a construção subtil de um sentido de adequação da escolha (Thaler, 2017), da oportunidade, que é apenas em parte controlada, em termos formais, pela organização:

"A administração chamou-me, convidou-me, namorou-me muito bem. Eu já sabia que havia um estigma... uma tradição nesta casa: 'Se queres crescer, tens de ir para fora'. Se se quiser ter visibilidade na empresa para crescer (em termos salariais, hierárquicos, ao nível do poder de decisão, da responsabilidade, do respeito), tem de se mostrar que se é capaz de ir para fora, para um mercado”. (Duarte; Grupo “Tabique”)

No universo do grupo "Luz de Sempre”, a administração da empresa indica que é relevante (que é decisivo) para o grupo e para os trabalhadores do grupo, "ganhar mundo". Trata-se de um discurso que veicula uma valorização institucional da mobilidade de contorno fundamentalmente positivo, desenvolvimentista. Trata-se de uma prática e de uma experiência pessoal desejável, distinta e distinguível de outras, não isenta de dificuldade(s), porém, em termos gestionários. Trata-se de uma prática que implica "cedências, mas também um acréscimo de coisas" (Joana; Silvestre). No grupo "Grossista”, ao invés, a natureza heteróclita, ambivalente, da prestação de trabalho que tem lugar num contexto de expatriação é salientada. Trata-se de uma modalidade de prestação de trabalho que comporta vantagens (a possibilidade de "ter mundo"), e que pode delimitar, em simultâneo, quadros de relação e de integração organizacional 
marcados pela "carência" e pela "privação" (o sentido de distância que advém da mobilidade).

Dada a necessidade de mobilização de pessoas e a incomensurabilidade desta mobilização no momento presente, no grupo "Tabique” observa-se um movimento deliberado de valorização institucional da experiência internacional como um “crescimento" (Duarte; Aurélio), de estar fora como uma putativa vantagem no desenvolvimento de uma carreira organizacional futura. $\mathrm{Na}$ empresa "V\&V", a periodização da mobilidade inerente a uma expatriação é definida de modo particularmente constrito (seis a doze meses), à luz de uma representação institucional onde se salienta um elemento de penosidade. Neste contexto empresarial, o discurso institucional não vinca ou vincula, de modo ostensivo, a mobilidade como condição de vantagem para os indivíduos. Há um esforço deliberado para a apresentação da mobilidade de modo neutral, e há, neste caso (como no caso do grupo "Luz de Sempre"), uma retribuição específica associada a um coeficiente de penosidade - a assim denominada “away-from-home compensation". Regista-se, neste contexto, um constrangimento particular ao nível da ação gestionária, que se exprime pela escassez de alternativas, pela rejeição de um convite:

“[As pessoas são convidadas, são sondadas?] Sim, as pessoas são sondadas. [As pessoas podem dizer que não?] Sim, podem dizer que não”. (Diretor de RH; Empresa "V\&V")

“[Há pouco foi referido que uma pessoa pode rejeitar um convite para expatriação. O que acontece?] Nada. Estamos num ponto agora em que somos muitos, onde temos falta de recursos e excesso de recursos, em simultâneo". (Gestor de Produção; Empresa "V\&V")

"As pessoas podem dizer que não a um convite? Podem... e muitas vezes dizem que não. Temos de aceitar a decisão da pessoa. Aliás, o pior cenário que poderíamos criar era enviar alguém para o cliente contrariado. No máximo, o que procuramos fazer é tentar convencer as pessoas que estão na dúvida. [À luz de que argumentos?] Explicar a importância de ser aquela pessoa, a confiança que há naquela pessoa. Depois, apelamos ao sentido de missão: a maior parte das pessoas que trabalha na empresa tem um gosto na marca, na imagem, que produz um efeito que pesa, que não é, porém, suficiente, por vezes, para as pessoas deixarem a sua família”. (Diretor de Produção; Empresa "V\&V") 


\section{Discussão}

Atendendo ao horizonte de problematização da pesquisa, importa considerar, na discussão dos resultados que foram apresentados, duas direções de exploração e interpretação que se interligam: 1) o convite como figura-signo que sinaliza a existência de processos de mobilização decorrentes de escolhas de contorno segmentário; 2) a existência de rejeições de convites, o papel conferido às relações pessoais, a necessidade de recurso a mecanismos de influência direta, como evidências empíricas que apresentam a mobilidade e a mobilização de um trabalhador expatriado (a expatriar), como campos de ação política (Dorow, Roseman \& Cresswell, 2017), onde a correspondência entre representação institucional da mobilidade e objetivos e práticas de mobilização não é unívoca ou direta.

“A regra pode ser outra, mas o comum é o convite" (Duarte). A existência de "convites", de "nomeações" (Francisco), contribui para sinalizar uma expatriação como uma situação de trabalho específica, uma situação de/para escolhidos. Não se trata de uma situação (de trabalho, de existência) como outras, não se trata de uma experiência para todos, não é uma experiência para quem quer, não é uma experiência, no limite, que se escolhe. Como foi mencionado, nos casos e nos contextos empresariais considerados, observou-se um recurso expressivo ao convite, à identificação direta de um trabalhador para efeito de mobilização. Há uma prevalência de convites, em particular, porque é necessário instituir e perseverar, num contexto (de internacionalização, mobilidade, mobilização) percebido como maculado pelo risco e pela incerteza, um sentido de confiança. Importa mobilizar os melhores (entre aqueles que se mostrem disponíveis). Os melhores são os que suscitam confiança, os que poderão suscitar confiança. A valorização da confiança como mecanismo de coordenação de escolhas decorre de exigências do contexto (do cliente, do projeto, da cultura da geografia de destino), e da necessidade de controlo do acesso a uma oportunidade (a mobilidade, uma expatriação) entendida como potencialmente conducente à aquisição de uma vantagem. Torna (ainda mais) exíguo o elenco de escolhas admissíveis: o cliente é exigente; o projeto é complexo; o contexto local é singular; o projeto é valioso, o projeto é inédito; é preciso mostrar competência, liderança na relação com o parceiro local.

A "visibilidade" (Filipe; Empresa "V\&V") e o reconhecimento que se antecipa poder decorrer do acesso a uma experiência (de trabalho, de mobilidade) que é valorizada, em termos institucionais, como distintiva, constitui um recorte motivacional particularmente mobilizador para os indivíduos entrevistados. A dimensão financeira é, de igual modo, um elemento de estímulo relevante. Aparenta contribuir apenas, porém, para assegurar a salubridade 
do enquadramento que é proporcionado pela empresa. Importa que a "compensação" (Filipe) facilite o consentimento (a ida), que assegure "conforto" (Dinis; empresa "Excel”), e não constitua, em si mesmo, um foco de conflito, um problema. A subsidiação material constrange a dissonância, assegura o consentimento, mas não a perenidade da motivação individual ou a ausência de rejeições de um convite. As "regalias" (Francisco) constituem em si mesmo, em simultâneo, um incentivo relevante à integração inicial num projeto de mobilidade e um forte desincentivo a um retorno sem atrito ou conflito.

Nos contextos empresariais e numa maioria dos 24 casos considerados não aparentam ser estes, todavia, os elementos decisivos na regulação de uma escolha individual (e.g., ir; não ir; concorrer a uma vaga interna). São múltiplas as referências a processos de mobilização cujo sucesso derivou, no essencial, de relações de proximidade, de um sentido de confiança pessoal. As referências e as relações pessoais, "relações que já se tinha de Portugal, alguém que conhece alguém, novas relações que se estabelecem diretamente, por necessidade" (Miguel), tidas como último reduto de "confiança" (Gil), desempenham um papel determinante a este nível, sendo, em várias ocasiões, o último recurso, o único recurso que se afigura disponível para assegurar uma dada mobilização individual, operando como figura de bypass ou complemento a uma prática formalmente definida. Em sectores e contextos particulares (e.g., empresa "V\&V"), tende a observar-se, a este propósito, uma condição de escassez (de alternativas), operando as referências e as relações pessoais como potencial fonte de mitigação ou balanceamento da mesma. A exposição, neste domínio, às referências e ao arbítrio pessoal, pode constituir uma fonte de vulnerabilidade para uma empresa, ao impossibilitar a generalização e a comparação dos processos decisórios. Em casos onde uma mobilização individual se afigura crítica para o sucesso de uma operação internacional específica ou para o próprio processo de internacionalização da empresa, depender de referências e de relações pessoais, do que é feito "em off" (Miguel), da "conversa poderosa com um diretor" (Carlos), ou de uma interpelação direta, de um "pedido de ajuda" (Isaac) do "CEO da empresa” (Nuno), apresenta a mobilização individual, num quadro de expatriação, como uma prática perpassada por um sentido de forte dependência face ao contexto.

\section{Conclusões}

As práticas de mobilização analisadas demonstram que a assimilação de uma representação institucional da mobilidade a uma condição de oportunidade, não se afigura unilinear e inequívoca. Este é um dado empírico significativo porquanto se afigura contrário à subsistência de uma imagem de controlo e elevada integridade organizacional, de emancipação face às vicissitudes de 
contexto, que tende a ser veiculada pelas empresas, em termos discursivos. Este é um dado empírico significativo ao demonstrar que o discurso organizacional, na sua orientação normativa, na sua consistência interna e na sua dimensão performativa, desempenha um papel determinante nos modos de mobilização e de definição institucional e pessoal de uma situação de mobilidade como a considerada enquanto caso e referente empírico (uma expatriação). Noutros termos: na mobilização (para a mobilidade), as palavras contam (produzem efeitos) na regulação social do consentimento (dos indivíduos), na produção de uma resistência seletiva, de um sentido de adequação de uma escolha (Thaler, 2017). A escolha de linguagem, o discurso de empresa, contribui decisivamente para definir uma mise-en-scene, um horizonte de socialização, de antecipação ou reconhecimento prévio das possibilidades objetivas associadas à condição de mobilidade. Como ilustrado, enaltecer, no plano discursivo, uma expatriação como experiência de privação ou, em sentido inverso, como uma oportunidade potencialmente conducente à aquisição de recursos de distinção individual, comporta implicações específicas. O que se diz e quem o diz, conta: constitui uma manifestação e um exercício de poder, cuja regulação obedece a uma economia de meios específica, a um campo onde a correspondência de objetivos organizacionais e individuais não se afigura linear, implicando a articulação in situ de pressões contraditórias.

\section{Referências bibliográficas}

ANDERSON, Barbara (2005), "Expatriate selection: Good management or good luck?", International Journal of Human Resource Management, 16 (4), 567-583.

BOURDIEU, Pierre (1989 [1977]), O poder simbólico, Lisboa: Difel.

BROOKFIELD GRS (2016), Global Mobility Trends Survey - 2016, New York: Brookfield.

CALIGIURI, Paula, \& Bonache, Jaime (2016), "Evolving and enduring challenges in global mobility”, Journal of World Business, 51, 127-141.

COSTAS, Jana (2013), "Problematizing mobility: A metaphor of stickiness, non-places and the kinetic elite", Organization Studies, 34 (10), 1467-1485.

CRESSWELL, T. (2006), On the move: Mobility in the modern western world, New York: Routledge.

DOHERTY, Noeleen, \& Dickmann, Michael (2009), "Exposing the symbolic capital of international assignments”, International Journal of Human Resource Management, 20 (2), 301-320.

DOROW, Sarah; Roseman, Sharon; \& Cresswell, Tim (2017), "Re-working mobilities: Emergent geographies of employment-related mobility”, Geography Compass, 11 (12).

EISENHARDT, Kathleen, \& Graebner, Melissa (2007), “Theory building from cases: Opportunities and challenges", Academy of Management Journal, 50, 25-32.

ELLIOTT, A., \& Urry, J. (2010), Mobile lives, London: Routledge.

GHERARDI, L. (2009), La mobilité ambigué: Espace, temps et pouvoir aux sommets de la sociéte contemporaine. Paris: Édition universitaires européennes.

HARRIS, Hilary, \& Brewster, Christopher (1999), “The coffee-machine system: How international selection really works", International Journal of Human Resource Management, 10 (3), 488-500.

MÄKELÄ, Kristiina, Bjorkman, Ingmar, \& Ehrnrooth, Mats (2010), "How do MNCs establish their talent pools? Influences on individuals' likehood of being labeled as talent”, Journal of World Business, 45 (2), 134-142. 
McKENNA, S., Ravishankar, M., \& Weir, D. (2015), "Critical perspectives on the globally mobile professional and managerial class”, Critical Perspectives on International Business, 11 (2), 118-121.

MOUZELIS, Nicos (2008), Modern and postmodern social theorizing: Bridging the divide, Cambridge: Cambridge University Press.

PEIXOTO, João (1998), As migrações dos quadros altamente qualificados em Portugal: Fluxos migratórios inter-regionais e internacionais, Tese de Doutoramento em Sociologia Económica e das Organizações e Mobilidade Intra-Organizacional, Lisboa: ISEG.

RAGIN, Charles, \& Amoroso, Lisa (2011), Constructing social research: The unity and diversity of method. New York: Sage.

SHENTON, Andrew, \& Hayter, Susan (2004), "Strategies for gaining access to organizations and informants in qualitative studies”, Education for Information, 22, 223-231.

STRAUSS, Anselm, \& Corbin, Juliet (1998), Basics of qualitative research. Techniques and procedures for developing grounded theory, Thousand Oaks, CA: Sage.

THALER, Richard (2017), Comportamento inadequado: A construção da economia comportamental, Lisboa: Actual Editora.

URRY, J. (2007), Mobilities. Cambridge: Polity Press. 